\title{
Why Do Firms Have "Purpose"? The Firm's Role as a Carrier of Identity and Reputation
}

\section{Citation}

Henderson, Rebecca, and Eric Van den Steen. 2015. "Why Do Firms Have 'Purpose'? The Firm's Role as a Carrier of Identity and Reputation." American Economic Review 105 (5) (May): 326-330. doi:10.1257/aer.p20151072.

\section{Permanent link}

http://nrs.harvard.edu/urn-3:HUL.InstRepos:33785676

\section{Terms of Use}

This article was downloaded from Harvard University's DASH repository, and is made available under the terms and conditions applicable to Open Access Policy Articles, as set forth at http:// nrs.harvard.edu/urn-3:HUL.InstRepos:dash.current.terms-of-use\#OAP

\section{Share Your Story}

The Harvard community has made this article openly available.

Please share how this access benefits you. Submit a story.

Accessibility 


\title{
Why do Firms have 'Purpose'? The Firm's Role as a Carrier of Identity and Reputation
}

\author{
By Rebecca Henderson and Eric Van den Steen*
}

Why do so many firms publicly espouse a 'purpose' beyond simple profit maximization? And why do so many managers and employees appear to care deeply about this purpose and to believe that it is critically important?

The consumer goods giant Unilever, for example, has committed to obtaining $100 \%$ of its agricultural inputs from sustainable sources by 2020, while Henry Schein, a distributor of medical and dental products, claims that one of its most important goals is the 'expansion of care to at risk groups'. Both firms appear to believe that purpose is critical to their success, even though it seems to imply significant costs without obvious commensurate gains.

While the economics literature suggests some potential explanations for the embrace of purpose, none seems to account for four closely related observations - derived from our own observations and the management literature - that seem critical. First, firm purpose appears to be almost invariably directed towards a prosocial goal, i.e., it offers some benefit to society. Second, employees usually care deeply about the firm's purpose: they know it and are often passionate about it. Third, this seems to hold true even for employees like accountants whose work is far removed from the activities that actually fulfill the purpose, and even when the firm's actions may seem to be somewhat modest. This seems surprising: while a hospital nurse may derive motivation and satisfaction from the intrinsic value of her work with patients, it seems

\footnotetext{
* Henderson: Harvard Business School, 15 Harvard Way, Boston, MA 02163, rhenderson@hbs.edu. Van den Steen: Harvard Business School, 15 Harvard Way, Boston, MA 02163, evandensteen@hbs.edu. We thank Bob Gibbons both for organizing the session and for many inspiring discussions, and the AEA participants for helpful comments.
}

unlikely that the hospital's accountant will derive the same type of satisfaction from doing the accounting. Fourth, firms try to show that the social engagement is 'authentic' in the sense that it is not done simply to make money. Motivation seems to count as much as action.

These observations appear to run counter to much of the existing literature. Consider first the common argument that firms that embrace purpose are 'doing well by doing good,' or that the pursuit of purpose often also directly increases profits. Bénabou and Tirole (2010) argue that this can make sense either when purpose can compensate for some form of managerial myopya, or when the firm's customers directly value the social impact. ${ }^{1}$ But if this is the case, why would most purposes be prosocial? Why would authenticity be important? A second set of explanations comes from the organizational economics literature that explores 'vision' and 'mission'. In particular, Rotemberg and Saloner (2000) showed that a manager's bias towards a particular course of action can increase employees' effort and investments, whereas Van den Steen (2005) showed that it can give direction, improve coordination, and attract employees with similar beliefs and values, which can then solve a range of agency problems (Van den Steen 2010). But why would such a vision be focused on a prosocial purpose? And why would managers seek to avoid the impression that having a purpose is simply the profitable thing to do?

\footnotetext{
${ }^{1}$ Bénabou and Tirole (2010) further suggest 'delegated philanthropy' as another explanation and argue that this may be effective when the firm is better at some philanthropic activity than its employees and shareholders. But it's unclear - at least in the absence of other motivations - why such delegated philanthropy is not done on a voluntary basis (like any other philanthropical organization) instead of bundling it with share ownership or employment.
} 
In this article, we propose that a firm's purpose can create value - beyond its social impact - by developing or strengthening employees' identity and reputation. ${ }^{2}$ We define 'purpose' as a concrete goal or objective for the firm that reaches beyond profit maximization; a person's 'reputation' as others' beliefs about that person, i.e., about her type; and a person's 'identity' as her own beliefs about herself and her type. $^{3}$ Our analysis builds on two findings from the psychology literature: first, that people care deeply about about having a positive identity and reputation; second, that people infer their identity at least in part from past behavior, i.e., that people infer their own preferences and values in part from looking at past choices (Fiske and Taylor 1991, Bénabou and Tirole 2011). Expanding on that literature, we hypothesize that firms can become effective "carriers' of identity and reputation since both firm membership and firm actions are very visible, and thus particularly salient sources for these types of inferences. Moreover, firms also enjoy scale effects - as the firm's actions reflect on many employees at once - and are long-lived.

We explore the implications of these ideas in a formal model that is sketched below and discussed in more detail in the online appendix. The key result of our analysis is that firms that adopt a purpose can, in fact, be more profitable than others, by strengthening employees' identity and reputation. These profits flow from the fact that employees accept lower wages - given the identity and reputation benefits from working for the firm - and that they also exert more effort. This effect is driven by a sorting mechanism that effectively 'creates' identity and reputation. If sociallyminded employees prefer to work for a firm

\footnotetext{
${ }^{2}$ Whereas the management literature has occasionally connected firm purpose to corporate identity (e.g., Sisodia, Wolfe and Sheth (2007)), this paper is concerned with individual identity and reputation. It is also explicitly focused on - and is very precise about one particular mechanism that we believe to be critical. While this may reduce generality, it also leads to more crisp predictions and new insights.

${ }^{3}$ Purpose is not necessarily different from mission but typically more concrete.
}

with purpose, then employees of such a firm will tend to be socially-minded, which, in its turn, will affect observers' (and the employees' own) inferences and beliefs about the employees. Sorting combined with purposeful action makes the employees identifiable as being socially minded and creates identity and reputation. (If employees were randomly allocated, firm purpose would have no identity and reputation effects.) For sorting to occur, however, we show that there must be a trade-off between profits and social impact: if the most profitable actions are also the socially most beneficial ones, then every firm will take social action and such actions will lose their power to identify socially minded employees and thus to create reputation and identity. Thus industry profits and social action can - paradoxically - actually increase when social actions become less profitable.

The article then derives a number of additional insights. First, the key element in this trade-off is the firm's (opportunity) cost of taking such action, as this is what makes it a credible signal. This implies that the reputation and identity effects can, in principle, be independent of the impact of the actions: even actions that may seem, at first sight, symbolic could potentially play this role - if they have sufficient signaling value. ${ }^{4}$ Moreover, as the reputation and identity effects are, in principle, also independent of the personal actions of employees (beyond joining the firm), even accountants will care about the firm's purpose. Second, an important factor in making the firm a more effective carrier of reputation and identity is whether identity and reputation are complements (in the utility function). We would expect this to be the case, since the psychology literature strongly suggests that people value consistency between identity and reputation. If identity and reputation are complements, employees who already have some inherent prosocial identity will care more about

\footnotetext{
${ }^{4}$ Obviously, we expect cost and social impact to be generally correlated since, in equilibrium, socially minded firms will only select the most costly actions if they have a large impact.
} 
developing a prosocial reputation and will thus value joining a firm with purpose more highly. Once they are members of the firm, the same complementarity will make them care even more about developing a prosocial identity. Inherently sociallyminded employees will thus (endogenously) care more about having a prosocial identity and reputation than other employees. A third insight of the model is that purpose is ultimately made credible through managers' values and beliefs - which create a relational contract by implicitly promising specific future actions in exchange for lower wages and more effort (Gibbons and Henderson 2013). Moreover, purpose generates in its turn corporate values and culture.

We now turn to a sketch of the formal model and the results, with a more detailed discussion in the online appendix.

\section{Model Sketch}

Consider a setting with $N \rightarrow \infty$ firms, each having 1 manager (M) and $K$ employees (E). Whereas the manager is exogenously attached to the firm, the employees will be matched to the firm - as part of the game (using the core) - from an infinite pool of potential employees. Both managers and employees have one of two types: Social $(S)$ or Asocial $(A)$. Exactly one of the managers and $L$ potential employees in the pool are of type $S$, with $K<L<\infty$.

Each firm will take an action from the set $\left\{X_{h}, X_{l}, Y_{l}, Y_{h}\right\}$, with each action $Z$ having both a monetary payoff $\mathcal{P}_{Z}$ and a social impact $\mathcal{B}_{Z}$ (which captures a benefit to society). The action is chosen either by a randomly selected employee (each with probability $\rho$ ) or by the manager (with complementary probability $1-K \rho \geq 0$ ). If an employee chooses the action, then the manager can overturn it at a cost $\delta \downarrow 0$ to both the manager and the employee. The monetary payoffs of the actions $\left\{X_{h}, X_{l}, Y_{l}, Y_{h}\right\}$ are respectively $P, P-\epsilon,-P+\epsilon$, and $-P$ for some $P>>\epsilon>0$. The social impacts $\mathcal{B}_{Z}$ are a permutation of $\{B, B, 0,0\}$ with $B>0$, where we will consider three cases: 1) positive correlation between $\mathcal{B}_{Z}$ and $\mathcal{P}_{Z}$ : the social impacts of $\left(X_{h}, X_{l}, Y_{l}, Y_{h}\right)$ are respectively $(B, B, 0,0)$ (i.e., 'doing well by doing good'), 2) no correlation (which is the most important case): the social impacts are a randomly selected permutation of $(B, B, 0,0)$ with all permutations equally likely, and 3 ) negative correlation: the respective social impacts are $(0,0, B, B)$. When selected, an employee can also exert effort (at personal cost $c$ ), which increases the probability that the firm's action is 'executed' - i.e., that it gives the payoff and impact discussed above and that it is observed - from $\psi$ to $(\psi+\delta) \in(0,1]$.

Whereas $A$-type players don't care about the social impact, $S$-type players who are personally involved in the choice get a private benefit $\gamma_{i} \mathcal{B}_{Z}$, with $i \in\{M, E\}, \gamma_{M}>0$, and $\gamma_{E} \geq 0$. We will say that an employee is personally involved when she is selected to make the choice, whereas the manager is always personally involved. In terms of the monetary payoffs (or incentives), each manager will get a share $\alpha_{M}$ of her firm's overall profit $\Pi$ (consisting of payoff $\mathcal{P}_{Z}$ minus employee wages) plus a wage that we normalize for simplicity to $w_{M}=0$. Employees get a share $\alpha_{E}$ of monetary payoffs $\mathcal{P}_{Z}$ plus a wage $w_{E}$ that is determined in the matching process, as part of the game. ${ }^{5}$

A key assumption of the model is that employees care not only about $\alpha_{E} \mathcal{P}_{Z}$ and $\gamma_{E} \mathcal{B}_{Z}$ but also about their identity and personal reputation, i.e., how they perceive themselves and how they are perceived by others. ${ }^{6}$ For some particular employee, let $\mu$ and $\nu$ denote respectively that employee's belief and the belief of an outsider (who observes only this employee and her firm) that the employee's type is $S$. The employee then gets an extra utility $U(\mu, \nu)=\lambda(\mu+$ $\nu)+(1-\lambda) \mu \nu$ for $\lambda \in[0,1]$. The fact that $U$ increases in $\mu$ and $\nu$ captures the desirability of an $S$-reputation/identity, whereas the

\footnotetext{
${ }^{5}$ As with other elements of the model, the specific assumptions are chosen to simplify the analysis. In this case, for example, giving the employee $\alpha_{E} \Pi$ or the manager $\alpha_{M} \mathcal{P}_{Z}$ gives qualitatively similar results but with more complex analysis.

${ }^{6}$ The online appendix shows how the results extend when the manager also cares about identity and reputation.
} 
complementarity between $\mu$ and $\nu$ reflects people's need for consistency between identity and reputation. The outsider forms his belief based on public and common knowledge about that employee: which firm the employee belongs to, that firm's action, and the equilibrium. With regard to the employee's belief about her own type, we make a second key assumption, along the lines of Bénabou and Tirole (2011): employees know their type when they make a payoffrelevant decision but forget in the last period with probability $q$ everything except for the public or common knowledge facts, and then need to infer their type as if they were an outsider.

Conditional on execution, the utility of an $A$ - and an $S$-manager is thus respectively $\alpha_{M} \Pi$ and $\alpha_{M} \Pi+\gamma_{M} \mathcal{B}_{Z}$; the utility of an $A$ employee and of an $S$-employee who does not choose the action is $\alpha_{E} \mathcal{P}_{Z}+U(\mu, \nu)$, whereas the utility of an $S$-employee who was selected to choose the action is $\alpha_{E} \mathcal{P}_{Z}+$ $\gamma_{E} \mathcal{B}_{Z}+U(\mu, \nu)$.

The timeline of the game is then as follows:

1) Hiring and selection

a) Employees are allocated to firms and wages are set according to a core solution (with equal wages within a firm). Non-matched players get outside option $w=0$ (plus $U(\mu, \nu)$ ).

b) One player is selected (to take action) in each firm. Each employee (resp. the manager) is selected with probability $\rho$ (resp. $1-K \rho$ ).

2) Actions

a) If the selected player is an employee, she decides whether to exert effort at cost $c$.

b) The social impact of the four alternatives are drawn and publicly revealed.

c) The selected player chooses an action.

d) The manager decides whether to overturn the action.
3) Payoffs

a) With probability $\psi$, the chosen action is executed and payoffs realized. (With complementary probability, the firm has no action.)

b) With probability $q$, players forget everything except for who belongs to which firm, the firms' actions, and the equilibrium.

c) Payoffs and utilities are realized.

A few additional remarks are in order. First, when there are multiple core solutions, one is picked at random with all being equally likely. Second, employee wages will be constrained to be identical within one firm but can differ across firms, reflecting the fact that the manager's type is more likely to be publicly known than that of a potential employee. We will also make a few parametric assumption that are explained in the online appendix: $\alpha_{E}, \alpha_{M}>0, \alpha_{M}>\alpha_{E}$, and $P-\epsilon / 2>$ $\max \left\{\gamma_{M} B, \gamma_{E} B, K U(1,1)\right\}$.

The proposition below captures the main insights from the analysis. A firm with an $S$ - or $A$-manager will be referred to as an $S$ - or $A$-firm.

PROPOSITION 1: - The S-firm is for an outsider indistinguishable from the $A$-firms in the case with positive correlation (between $\mathcal{P}_{Z}$ and $\mathcal{B}_{Z}$ ), and in the cases with sufficiently low $\gamma_{M} B$.

- The $S$-firm can have higher profits than the $A$-firms (even when $\rho \gamma_{E} B=0$ ), both in the case with no correlation and in the case with negative correlation and effort. In such cases, S-employees have a social reputation and identity, accept lower wages, and exert more effort. Industry profits are higher and social impact can also be higher than in the above case with indistinguishable firms. The profit difference increases in firm size $K$ and employee involvement $\rho$. With no correlation or effort, profits are highest at intermediate levels of $\gamma_{M} B$. 
- The S-firm has lower profits than the A-firms in some (but not all) cases with negative correlation - when $S$ employees' lower wages do not make up for the lower monetary payoffs.

- Whenever $\lambda=1$ ('no complementarity') and $\rho \gamma_{E} B=0$, the $S$-firm has lower profits than the $A$-firms. In such cases, the $S$-firm chooses the social action, but its employees are randomly drawn, have no social reputation, and are paid the same as A-firm employees.

\section{Conclusion}

This article developed a theory in which a firm's adoption of a prosocial purpose can increase profitability by strengthening employees' reputation and identity - leading to higher effort and lower wages - as long as implementing purpose is costly with respect to direct monetary payoffs. Employees who value prosocial action will select into firms with a social purpose, which then become a visible carrier for these employees' identity and reputation.

While this model is consistent with many of the stylized facts around firm purpose, it also raises important questions for further research, such as empirical tests of the theory or further analysis of the relationship to relational contracts or culture. We hope that it inspires further work in this direction.

\section{REFERENCES}

Bénabou, Roland, and Jean Tirole. 2010. "Individual and Corporate Social Responsibility." Economica, 77(305): 119.

Bénabou, Roland, and Jean Tirole. 2011. "Identity, Morals, and Taboos: Beliefs as Assets." Quarterly Journal of Economics, 126: 805-855.

Fiske, Susan, and Shelley Taylor. 1991. Social Cognition. New York:McGraw-Hill.

Gibbons, Robert, and Rebecca Henderson. 2013. "What Do Managers Do? Exploring Persistent Performance Differences Among Seemingly Similar Enterprises." In The Handbook of Organiza- tional Economics., ed. Robert Gibbons and D. John Roberts. Princeton University Press.

Rotemberg, Julio J., and Garth Saloner. 2000. "Visionaries, Managers, and Strategic Direction." Rand Journal of Economics, 31(4): 693- 716.

Sisodia, Rajendra S., David B. Wolfe, and Jagdish N. Sheth. 2007. Firms of Endearment: How World-Class Companies Profit from Passion and Purpose. Wharton School Publishing.

Van den Steen, Eric. 2005. "Organizational Beliefs and Managerial Vision." Journal of Law, Economics, and Organization, 21(1): 256- 283.

Van den Steen, Eric. 2010. "Culture Clash: The Costs and Benefits of Homogeneity." Management Science, 56(10): 1718-1738. 